\title{
Expression of the mevalonate pathway enzymes in the Lutzomyia longipalpis (Diptera: Psychodidae) sex pheromone gland demonstrated by an integrated proteomic approach
}

\author{
Natalia González-Caballero ${ }^{a}$, Andrés Rodríguez-Vega $^{b}$, Geovane Dias-Lopes $^{c}$, \\ Jesus G. Valenzuela ${ }^{d}$, Jose M.C. Ribeiro ${ }^{e}$, Paulo Costa Carvalho ${ }^{f}$, Richard H. Valente ${ }^{g}$, \\ Reginaldo P. Brazil ${ }^{a}$, Patricia Cuervo, ${ }^{b, *}$ \\ ${ }^{a}$ Laboratório de Bioquímica e Fisiologia de Insetos, IOC, FIOCRUZ, Rio de Janeiro, RJ, Brazil \\ ${ }^{b}$ Laboratório de Pesquisa em Leishmaniose, IOC, FIOCRUZ, Rio de Janeiro, RJ, Brazil \\ 'Pós-graduação Biologia Parasitaria, IOC, FIOCRUZ, Rio de Janeiro, RJ, Brazil \\ ${ }^{\mathrm{d}}$ Vector Molecular Biology Section, Laboratory of Malaria and Vector Research, National Institutes of Health Rockuille, MD, USA \\ eVector Biology Section, Laboratory of Malaria and Vector Research, National Institutes of Health Rockuille, MD, USA

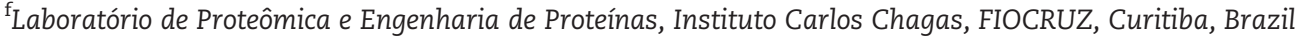 \\ gLaboratório de Toxinologia, IOC, FIOCRUZ, Rio de Janeiro, RJ, Brazil
}

\section{A R T I C L E I N F O}

Article history:

Received 2 June 2013

Accepted 19 October 2013

Available online 1 November 2013

Keywords:

Lutzomyia longipalpis

Male pheromone gland

Proteomics

Proteome

Mevalonate pathway

\begin{abstract}
A B S T R A C T
In Latin America, Lutzomyia longipalpis is the main vector of the protozoan parasite Leishmania infantum, which is the causal agent of American Visceral Leishmaniasis. This insect uses male-produced pheromones for mate recognition. Elucidation of pheromone biogenesis or its regulation may enable molecular strategies for mating disruption and, consequently, the vector's population management. Motivated by our recent results of the transcriptomic characterization of the L. longipalpis pheromone gland, we performed a proteomic analysis of this tissue combining SDS-PAGE, and mass spectrometry followed by an integrative data analysis. Considering that annotated genome sequences of this sand fly are not available, we designed an alternative workflow searching MS/MS data against two customized databases using three search engines: Mascot, OMSSA and ProLuCID. A total of 542 proteins were confidently characterized, 445 of them using a Uniref100-insect protein database, and 97 using a transcript translated database. In addition, use of PEAKS for de novo peptide sequencing of MS/ MS data confirmed $~ 90 \%$ identifications made with the combination of the three search engines. Our results include the identification of six of the seven enzymes of the mevalonate-pathway, plus the enzymes involved in sesquiterpenoid biosynthesis, all of which are proposed to be involved in pheromone production in L. longipalpis.
\end{abstract}

Biological significance

L. longipalpis is the main vector of the protozoan parasite L. infantum, which is the causal agent of American Visceral Leishmaniasis. One of the control measures of such disease is focused on vector population control. As this insect uses male-produced pheromones for mate recognition,

\footnotetext{
* Corresponding author at: Laboratório de Pesquisa em Leishmaniose, Instituto Oswaldo Cruz, FIOCRUZ, Av. Brasil 4365, Manguinhos, Pav. Leônidas Deane, Sala 509 Rio de Janeiro, RJ 21040-360, Brasil. Tel.: +55 2138658224.

E-mail address: pcuervo@fiocruz.br (P. Cuervo).
} 
the elucidation of pheromone biogenesis or its regulating process may enable molecular strategies for mating disruption and, consequently, this vector's population management. On this regard, in this manuscript we report expression evidence, at the protein level, of several molecules potentially involved in the pheromone production of L. longipalpis. Our results include the identification of the mevalonate-pathway enzymes, plus the enzymes involved in sesquiterpenoid biosynthesis, all of which are proposed to be involved in pheromone production in L. longipalpis. In addition, considering that the annotated genome sequences of this sand fly are not yet available, we designed an alternative workflow searching MS/MS data against proteomic and transcript translated customized databases, using three search engines: Mascot, OMSSA, and ProLuCID. In addition, a de novo peptide sequencing software (PEAKS) was used to further analyze the MS/MS data. This approach made it possible to identify and annotate 542 proteins for the pheromone gland of L. longipalpis. Importantly, all annotated protein sequences and raw data are available for the research community in protein repositories that provide free access to the data.

(C) 2013 Elsevier B.V. All rights reserved.

\section{Introduction}

Visceral leishmaniasis (VL) is the most severe form of leishmaniasis, with a global annual incidence of 0.2 to 0.4 million cases, of which $90 \%$ occur in India, Bangladesh, Sudan, South Sudan, Ethiopia and Brazil [1]. In the Neotropics, this disease is produced by the protozoan parasite Leishmania infantum [2], which is mainly disseminated by the sand fly Lutzomyia longipalpis (Lutz \& Neiva, 1912) Psychodidae: Phlebotominae (reviewed in [3]). This sand fly species can be found in different habitats ranging from Mexico to northern Argentina [4-6]. As adult sand flies, females and males can find nutrients from natural sources such as honeydew or plant juices [7]. Alternatively, females can feed on animal blood, which is necessary for successful oviposition [8]. During the blood-feeding process, infected sand flies can transmit Leishmania to animals present in a variety of epidemiological cycles [9]. Although parasite transmission occurs primarily in rural areas, recent reports have shown the increase of VL incidence around large cities [10-12]. Such adaptation to human-modified environments reflects this vector's ability to occupy a wide range of ecologic niches (reviewed in [3]).

Male sand fly aggregation occurs near, or on, vertebrate hosts during female blood-feeding. Males arrive to the vertebrate hosts, before females, triggering lure dynamics that attract females. The first L. longipalpis male arriving to a vertebrate host primes the aggregation formation by producing pheromones that attract other males, which in turn produce more pheromones attracting even more flies [13]. Consequently, virgin females are attracted to male pheromones which are synergized by the host's odor [14].

The main components of sex pheromone blends in different populations of L. longipalpis have been characterized as terpenoid compounds. To date, two different homosesquiterpenes (C16) have been structurally identified as (S)-9-methylgermacrene-B (9MGB) and 3-methyl-a-himachalene (3MaH) [15-18]. Two other terpenoid monocyclic (C20) pheromones have been partially identified as cembrene isomers referred to as cembrene 1 and cembrene 2 [19,20]. Terpenoids (or isoprenoids) originate through the condensation of isopentenyl diphosphate (IPP) and dimethylallyl diphosphate (DMAPP), which are the assembling block molecules (C5) of nearly all isoprenoid [21]. In higher eukaryotes and some bacteria, IPP and DMAPP are produced by a cellular metabolic pathway described as the mevalonate pathway or mevalonate dependent pathway MDP [22]. Three acetyl-
CoA molecules need to be condensed to generate IPP and its isomer DMAPP. IPP then undergoes successive condensations with DMAPP to produce farnesyl pyrophosphate synthase FPP [23]. In most animals, the most studied final product of the mevalonate pathway is cholesterol because of its implication with cardiovascular disease [22]. Insects, however, cannot synthesize cholesterol de novo [24] because they are deficient in enzymes such as the squalene synthase and the lanosterol synthase [25-27]. Consequently, and contrary to those reactions needed to obtain FPP from acetyl-CoA, the enzymes associated to the mevalonate pathway are not homologous to those of cholesterol-producing organisms (reviewed in [28]). In insects, these reactions have been mostly described as result of the elucidation of the juvenile hormone $(\mathrm{JH})$ biosynthetic steps, which occurs in a glandular tissue, the corpora allata (CA) [29-32].

In L. longipalpis, terpenoid sex pheromones are produced in glands located under the cuticle of pale patches on male abdominal segments. In these pale patch structures a number of gland cells are connected to the exterior via small cuticular ducts [33]. Recent studies correlating pheromone production to glandular cell morphogenesis have reported that pheromone biosynthesis begins approximately $12 \mathrm{~h}$ after adult emergence and increases constantly during the first three days, stabilizing afterward [34]. Different L. longipalpis populations produce and respond to different sex pheromones, a characteristic that has been exploited for phylogenetic purposes [20]. It has been proposed that pheromone biosynthesis in L. longipalpis involves the enzymes of the mevalonate pathway as well as prenyltransferases [35]; however, evidence for the expression of these enzymes, at the protein level, in the pheromone gland of the sand fly is lacking.

The elucidation of pheromone biogenesis or the mechanisms that may be regulating this process may enable molecular strategies for mating disruption and, consequently, sand fly population management. In this regard, describing the profile of proteins in the pheromone gland represents a first step toward comprehending the biosynthetic process occurring in this specialized tissue. Motivated by our recent results on the transcriptomic characterization of L. longipalpis' pheromone gland that reports mRNA evidence for several enzymes of the mevalonate pathway [35], we performed a robust and in-depth bioinformatics analysis of high-resolution proteomic data of this tissue to pinpoint protein evidence, correlated to transcriptomic 
data, and ultimately provide insights on the pheromone glands protein functions. As genome sequences of L. longipalpis are not yet available, to maximize the proteomic analysis of the pheromone gland, the MS/MS datasets obtained in this study were analyzed using three different search engines combined with a customized insect protein database and also our own transcript translated database. This workflow enabled a highly confident proteomic characterization of the pheromone gland and allowed the identification of mevalonate pathway enzymes potentially involved in the L. longipalpis pheromone production.

\section{Methods}

\subsection{Chemicals}

Laboratory chemicals were purchased from Sigma Chemicals St. Louis, MO, USA or Merck São Paulo, SP, Brazil. MilliQ-purified water Millipore Corp., Bedford, MA, USA was used to prepare all solutions.

\subsection{Insects}

The experiments were performed using 3 to 7 day old L. longipalpis Diptera: Psychodidae one-spot adult males. The insects were captured from Gruta da Lapinha, Municipality of Lagoa Santa, Minas Gerais, Brazil, $19^{\circ} 38 \mathrm{~S} ; 43^{\circ} 53 \mathrm{~W}$ and colonized at the Laboratório de Bioquímica e Fisiologia de Insetos at the Instituto Oswaldo Cruz, Rio de Janeiro, Brazil. Colony maintenance procedures followed those previously described [8] including a temperature of $26^{\circ} \mathrm{C}, 80 \%$ relative humidity, and 12:12 LD photoperiod. We used insects from the 1st to 7 th generations after checking for their (S)-9-methylgermacrene-B production according to [15]. Permission for sand fly collection was obtained from the Brazilian Ministry of Environment (SISBIO\#26066-1).

\subsection{Pheromone gland dissection and protein extraction}

Cold-anesthetized male insects were carefully dissected using a stereoscopic microscope $6 x$ to $40 x$ in sterilized conditions in order to minimize any risk of contamination. Following decapitation and midgut removal, insect abdomens were washed in a sterilized $0.9 \%$ saline solution and ultrapure water. Pheromone glands from one hundred males were dissected, pooled and lysed in $100 \mu \mathrm{L}$ of $2 \mathrm{M}$ thiourea, $7 \mathrm{M}$ urea, 4\% CHAPS, $65 \mathrm{mM}$ DTT and a protease inhibitor cocktail (complete protease inhibitor cocktail, Roche) that is intended to inhibit serine, cysteine and metalloproteases. Lysis proceeded with ten cycles of freeze (liquid nitrogen)/thaw/sonication. Sonication was carried out with a Fisher Sonic Dismembrator with an output frequency of $20 \mathrm{kHz}, 15 \%$ amplitude for $20 \mathrm{~s}$. To remove insoluble material, the samples were centrifuged at 10,000 $\times \mathrm{g}$ for $10 \mathrm{~min}$ at $4{ }^{\circ} \mathrm{C}$, the resulting supernatant was precipitated with methanol: chloroform, 3:1. The proteins were resuspended in SDS sample buffer and the total protein concentration was measured using the Thermo Scientific Pierce 660 nm Protein Assay.

\subsection{SDS-PAGE, protein digestion and peptide extraction}

Aliquots of pheromone gland extracts containing $40 \mu \mathrm{g}$ of proteins were separated by $12 \%$ SDS-PAGE $30 \%$ acrylamide, $0,8 \%$ bis-acrylamide. The proteins were stained using Coomassie Brilliant Blue and photo-documented using a GS-800' ${ }^{\mathrm{TM}}$ calibrated imaging densitometer Bio-Rad. The proteins were enzymatically digested following procedures previously described [36] with some modifications. Briefly, lanes containing proteins were finely sliced and each slice was destained three times in $400 \mu \mathrm{L}$ of $50 \%$ acetonitrile, $25 \mathrm{mM} \mathrm{NH}_{4} \mathrm{HCO}_{3} \mathrm{pH} 8.0$ for $15 \mathrm{~min}$. The proteins were reduced in $65 \mathrm{mM}$ of DTT for $30 \mathrm{~min}$ at $56^{\circ} \mathrm{C}$ and then alkylated with $200 \mathrm{mM}$ iodoacetamide at $25^{\circ} \mathrm{C}$ in darkness for $30 \mathrm{~min}$. The gel slices were washed with $100 \mathrm{mM} \mathrm{NH}_{4} \mathrm{HCO}_{3}$ for $10 \mathrm{~min}$ followed by dehydration with acetonitrile for $5 \mathrm{~min}$. The slices were rehydrated with a solution of $20 \mathrm{ng} / \mu \mathrm{L}$ of sequencing grade modified porcine trypsin (Promega, USA) in $50 \mathrm{mM}$ $\mathrm{NH}_{4} \mathrm{HCO}_{3}$ and incubated overnight at $37^{\circ} \mathrm{C}$. Peptides were extracted using $0.1 \%$ formic acid in $50 \% \mathrm{v} / \mathrm{v}$ acetronitrile, desalted and concentrated with Poros oligo R3 resin (Applied Biosystems, USA).

\subsection{Mass spectrometry analysis}

Tryptic digests, obtained as described in the previous step, were submitted to reversed-phase nanochromatography coupled to nanoelectrospray high resolution mass spectrometry for identification. For each sample, $4 \mu \mathrm{L}$ of desalted tryptic peptide digest were initially applied to a $2-\mathrm{cm}$ long (100 $\mu \mathrm{m}$ internal diameter) trap column packed with $5 \mu \mathrm{m}, 200 \mathrm{~A}$ Magic C18 AQ matrix (Michrom Bioresources, USA) followed by separation on a $10.5-\mathrm{cm}$ long (75 $\mu \mathrm{m}$ internal diameter) separation column that was packed with the same matrix, directly on a self-pack $15 \mu \mathrm{m}$ PicoFrit empty column (New Objective, USA). Chromatography was carried out on an EASY-nLC II instrument (Thermo Scientific, USA). The samples were loaded onto the trap column at $2000 \mathrm{~nL} / \mathrm{min}$ while chromatographic separation occurred at $200 \mathrm{~nL} / \mathrm{min}$. Mobile phase A consisted of $0.1 \%(\mathrm{v} / \mathrm{v})$ formic acid in water while mobile phase $\mathrm{B}$ consisted of $0.1 \%(\mathrm{v} / \mathrm{v})$ formic acid in acetonitrile and gradient conditions were as follows: 2 to $40 \%$ B in $32 \mathrm{~min}$; up to $80 \% \mathrm{~B}$ in $4 \mathrm{~min}$, maintaining at this concentration for 2 min more. Eluted peptides were directly introduced to an LTQ/Orbitrap XL mass spectrometer (Thermo, USA) for analysis. Source voltage was set to $1.9 \mathrm{kV}$, capillary temperature to $200{ }^{\circ} \mathrm{C}$ and tube lens voltage to $100 \mathrm{~V}$. Ion trap full and MSn AGC target values were 30,000 and 10,000, respectively, while the FTMS full AGC target was set to 500,000 . MS1 spectra were acquired on the Orbitrap analyzer (300 to $1,700 \mathrm{~m} / \mathrm{z}$ ) at a 60,000 resolution (for $m / z=445.1200$ ). For each spectra, the 10 most intense ions were submitted to CID fragmentation (minimum signal required of 10,000; isolation width of 2.5; normalized collision energy of 35.0; activation $\mathrm{Q}$ of 0.25 and activation time of $30 \mathrm{~ms}$ ) followed by MS2 acquisition on the linear trap analyzer. Dynamic exclusion option was enabled and set with the following values for each parameter: repeat count $=1$; repeat duration $=30 \mathrm{~s}$; exclusion list size $=500$; exclusion duration $=45 \mathrm{~s}$ and exclusion mass width $=10 \mathrm{ppm}$. Charge state rejection was enabled for unassigned charges and for those equal to one. The experiments were performed using three biological replicates.

\subsection{Peaklist settings and databases searching}

MS raw files for each lane were converted to mzXML or MGF format using Mass Matrix MS Data File converter V. 3.9 
http://www.massmatrix.net/mm-cgi/downloads.py and to .MS2 format using RawReader in the PatternLab platform tools [37] http://proteomics.fiocruz.br/Softwares.aspx. In order to maximize search sensitivity and protein identification, data from each replicate were merged into a single file and searched using ProLuCID 1.3 in the PatternLab platform [38], OMSSA [39] in the Proteomatic platform 1.2.1 [40] http://www.proteomatic. org/download.html, and Mascot Daemon 2.3.02 http://www. matrixscience.com/daemon_support_v2_3.html. As annotated genome sequences of L. longipalpis are not available, data were searched against a customized database including non-redundant sequences for the Insecta Class downloaded October 2012 from UniRef100 [41] http://www.uniprot.org/ with 592,178 entries, and against the pheromone gland transcriptome protein database previously generated for L. longipalpis (1387 translated sequences [35]). Searches estimated peptide identification false discovery rates (FDRs) using identification from the reversed decoy database. Searches were performed with one missed cleavage, fixed modification of cysteine (carbamidomethylation), variable modification of methionine (oxidation) and mass tolerances of 2.0 and $0.8 \mathrm{Da}$ in OMSSA, $10 \mathrm{ppm}$ and $0.4 \mathrm{Da}$ in Mascot, 50 ppm and 500 ppm in ProLuCID for precursor and fragment ions, respectively.

The validity of the peptide sequence matches (PSMs) searched with ProLuCID were assessed using the Search Engine Processor (SEPro)[37]. Briefly, identifications were grouped by charge state $(+2$ and $\geq+3)$ and then by tryptic status (fully tryptic, semi-tryptic), resulting in four distinct subgroups. For each result, the ProLuCID XCorr, DeltaCN and ZScore values were used to generate a Bayesian discriminator. The identifications were sorted in a non-decreasing order according to the discriminator score. A cutoff score was established to accept a false-discovery rate (FDR) of $1 \%$ based on the number of labeled decoys. This procedure was independently performed on each data subset, resulting in a false-positive rate that was independent of tryptic status or charge state. Additionally, a minimum sequence length of six amino acid residues was required. The results were post-processed to only accept PSMs with less than $10 \mathrm{ppm}$ and proteins supported by two or more independent evidences (e.g., identification of a peptide with different charge states, a modified and a non-modified version of the same peptide, or two different peptides). This last filter led to a 0\% FDR in all search results.

For the other search engines, peptide candidates were filtered with $2 \%$ peptide FDR and 2 peptides per protein minimum. In addition, data resulting from OMSSA searches were manually analyzed and cured. Peptides identified with each search engine were manually re-checked and clustered together if peptide identifications were shared among different insect species, as this indicates considerable sequence similarity. The identification in the closest species to Lutzomyia was considered as the leader protein. This leader protein was considered a unique protein identifier. Furthermore, proteins identified and cured from the multiple search engines were clustered and organized in a single table. In addition, MS data were searched against our own transcript translated FASTA database using ProLuCID tool [35]. Furthermore, de novo peptide sequencing and peptidespectrum matching (PSM) of MS/MS spectra data were performed with PEAKS 6 (build 20120620) [90], using PEAKS De Novo and
PEAKS DB options, respectively. PEAKS DB tool combines PSM results and de novo peptide sequencing data to match proteins in the target database to be searched. Such a tool was used in combination with our customized Insecta database. Proteins identified by PEAKS DB were filtered for a minimum score $(-10 \lg P)$ of 40 and at least 2 peptides per protein. The acceptable false discovery rate for peptide identification was set to $1 \%$ at most.

The Gene Ontology Explorer tool at the PatternLab platform [42] was used to assign molecular and biological function to identified proteins. Moreover, for assignment of predicted functional domain, proteins of unknown function were analyzed with the InterProScan engine http://www.ebi.ac.uk/ Tools/pfa/iprscan/ $[43,44]$. In addition, functional associations among proteins potentially involved in pheromone production were confirmed by an in silico analysis using the STRING 9.0 server, a database that provides information about known and predicted protein interactions http://www.string-db.org $[57,58]$. The data was analyzed following the standards proposed under the Minimum Information About a Proteomic Experiment MIAPE consensus [45]. MS/MS data and identified proteins (Mascot and OMSSA) were deposited in the ProteomeXchange via the PRIDE repository [46]. The raw data together with all identifications via ProLuCID are available at http://max.ioc.fiocruz.br/natalia130430/.

\section{Results and discussion}

\subsection{Analysis of the pheromone gland proteome using Insecta database searching}

Pheromone gland tissues from L. longipalpis males were dissected, pooled for protein extraction, and fractionated by SDS-PAGE (Fig. 1). These preparations represent a reliable tool for studying the pheromone gland of this sand fly. In general, when annotated genome sequences are available, the identification of MS-based proteomics data relies on the match of spectra to these sequences. However, there are no annotated genome sequences of L. longipalpis yet and data related to gene expression in pheromone glands from insects are also scarce. To deal with this obstacle, we designed an alternative data analysis method for protein identification searching MS/MS data against a database that included sequences available for Insecta Class in UniProt (UniRef100), totalizing 592,178 entries (October 2012). The UniRef100 database contains non-redundant reference clusters for proteins from all insect species found in UniProt. Our rationale was that this search space would be broad enough to allow identification of L. longipalpis proteins by similarity, but also narrow enough to diminish both the false positives and the time consumed by the search. In addition, in order to maximize our results, we used three different search engines that allowed a significant increase in peptide identification (Fig. 2). In total, 445 proteins were identified against the Insecta database (Supplementary Table 1). Among these proteins, 140 (31\%) were commonly identified by the three engines and 316 (71\%) were identified by at least two search engines (Fig. 3, Supplementary Table 2). The results obtained with each engine are presented in Supplementary Tables 3, 4 and 5. The use of the Insecta database obtained from UniRef100 guaranteed us avoiding redundancies 


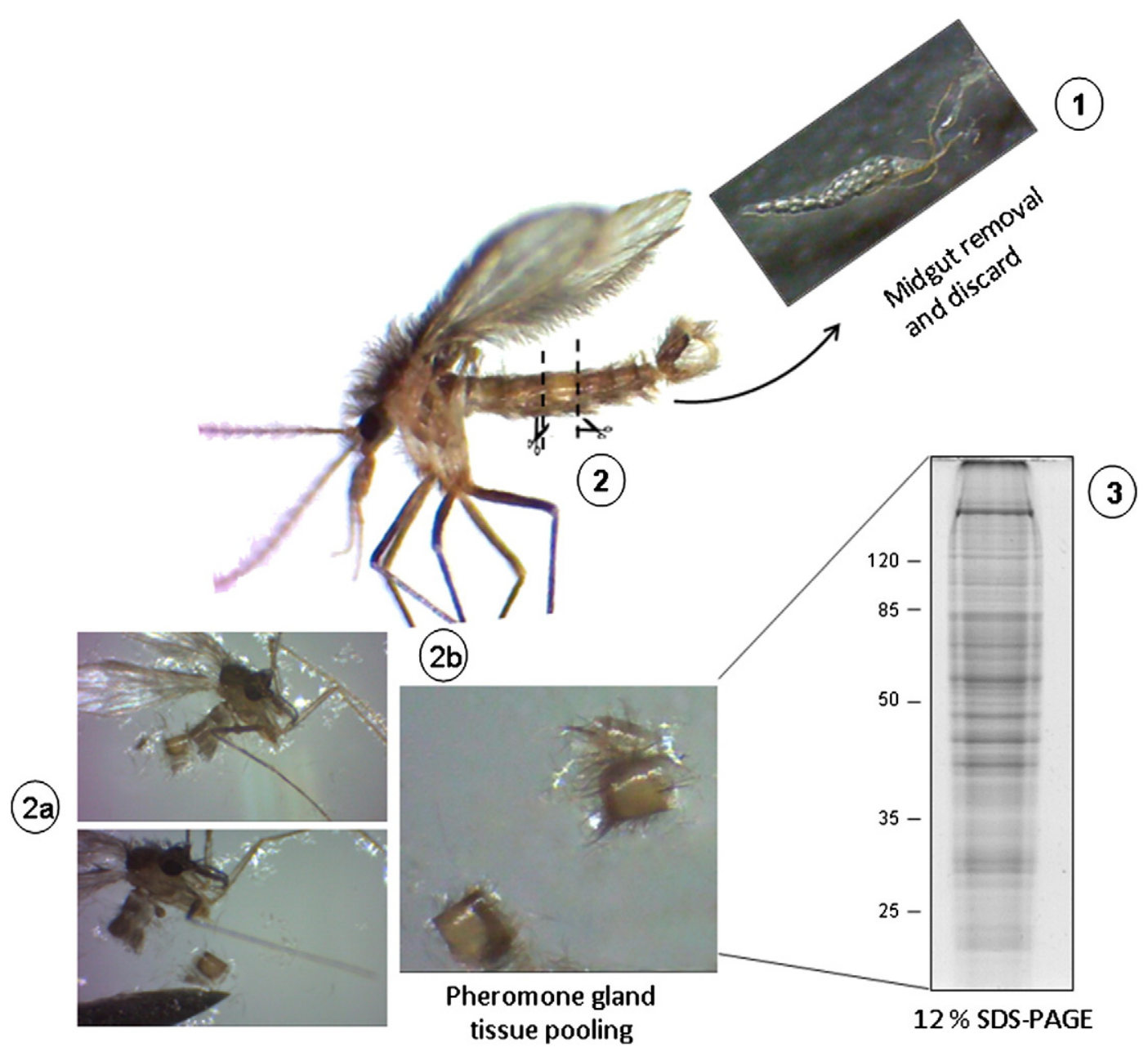

Fig. 1 - Dissection strategy used to isolate the 4th abdominal segment of L. longipalpis males which contains the pheromone gland. First, the integral midgut was carefully removed and discarded (1). Next, the 4th abdominal segment was cut out from the remaining abdominal segments (2) with the help of a tip of a needle of $20 \mathrm{~mm}(2 \mathrm{a})$. After thoroughly washing in $0.9 \%$ saline solution, a pool of approximately 100 segments (2b) was used for protein extraction and SDS-PAGE analysis (3).

in protein identification as different insect species can exhibit many isoforms of the same protein. Therefore, the 445 proteins identified in the pheromone gland preparations correspond to unique protein entries. Based on these non-redundant clusters we proceeded to analyze the insect species or insect families that contributed more for the similarity-based identification of L. longipalpis pheromone gland proteins. We observed that L. longipalpis proteins were identified by similarity mostly to proteins of insects from the Diptera order (68\%). Among Diptera, the Culicidae family, followed by the Drosophilidae family contributed $55 \%$ and $27 \%$ of the identifications, respectively (Fig. 4, Supplementary Table 6). The Psychodidae, which is the family that the Lutzomyia genus belongs to, contributed only $6 \%$ of the identifications (Fig. 4A). In fact, only 15 proteins were identified by match with L. longipalpis deposited sequences (Supplementary Table 1). Among the Culicidae species, Aedes aegypti, Culex quinquefasciatus and Anopheles gambie contributed $\sim 30 \%$ of the identifications (Fig. 4B). Our multi-engine search and identification approach was further verified by the PEAKS 6 de novo sequencing and database search (Fig. 2), which corroborated $90 \%$ of the identifications obtained with at least two engines (Supplementary Table 7).
3.2. Proteins involved in organic cyclic and heterocyclic compound binding enrich the pheromone gland proteome

Very little is known about L. longipalpis global or tissue specific protein expression patterns. Much less is known about protein function and functional associations. The use of the Gene Ontology Explorer tool showed that among the identified proteins $\sim 46 \%$ have a molecular function assigned, $\sim 35 \%$ participate in a known biological process, and only $19 \%$ could be assigned to a cellular component (Supplementary Fig. 1; Supplementary Table 8). Gene ontology classification based on molecular function showed that proteins involved in the binding of organic cyclic and heterocyclic compounds are enriched in our analysis, accounting for $\sim 37 \%$ proteins. In addition, transferases and oxidoreductases accounted for $\sim 12 \%$ of proteins with molecular functions assigned. The enzymes of the mevalonate pathway related to pheromone metabolism are classified in these categories. Additionally, the molecular function of hydrolases could be assigned to $~ 8 \%$ identified proteins. Hydrolases, specifically endopeptidases, are involved in the proteolysis process for farnesal production $[47,48]$, which is an intermediate in the sesquiterpenoid backbone synthesis $[49,50]$. Our results 


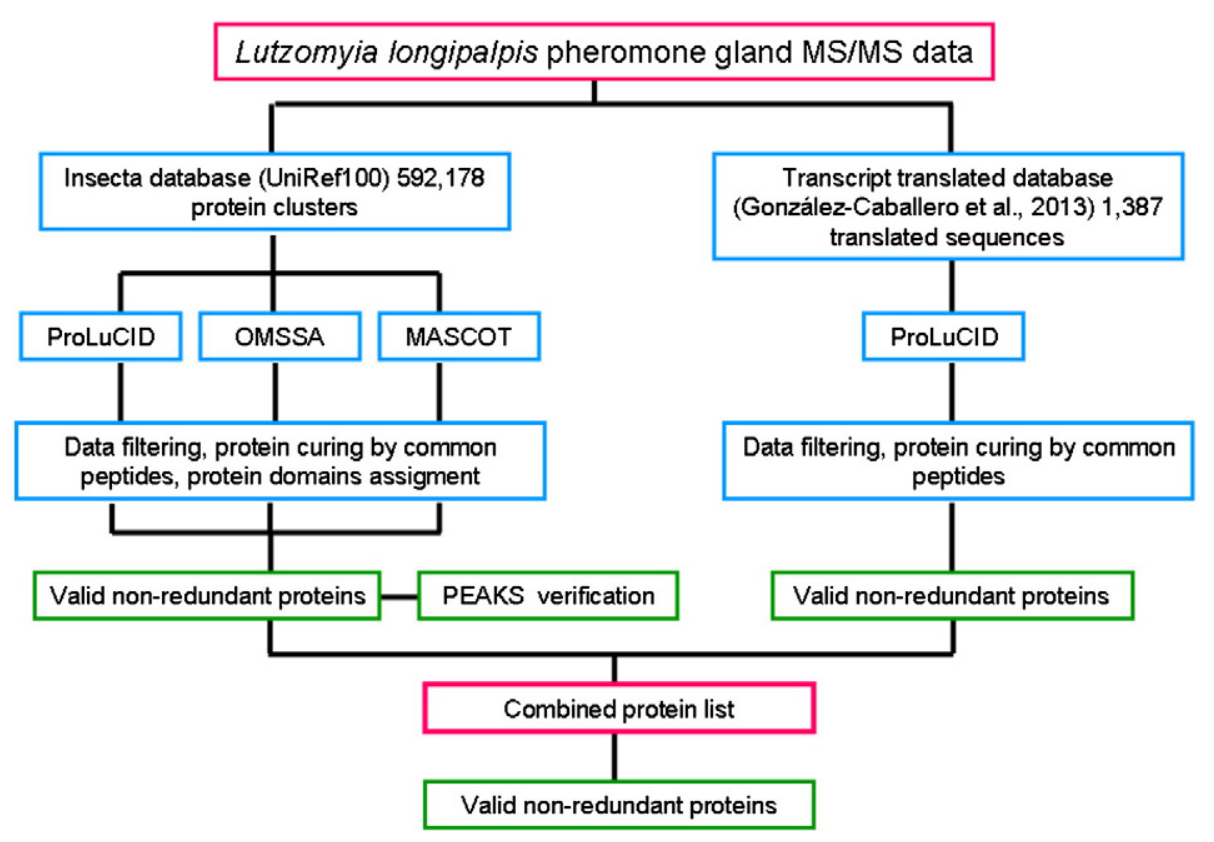

Fig. 2 - Proteomics data analysis workflow. Mass spectra data from proteins of L. longipalpis pheromone gland was searched against the Insecta database (Uniref100; 592,178 protein clusters), downloaded from UniProt, using three search engines: Mascot, OMSSA and ProLuCID Proteins identified with these search engines were verified by de novo sequencing and peptide spectrum matching using PEAKS (left). In addition, MS/MS data were analyzed against the pheromone gland transcript translated database previously obtained and reported (1387 translated sequences; [35]) using the ProLuCID search engine (right). Results were manually filtered and validated separately as described in the Methods section. The data obtained with the two databases were compared and combined in a list containing all non-redundant validated proteins.

also show that half of the identified proteins $(49 \%, 218 / 445)$ are annotated as uncharacterized proteins or do not have any associated putative function (Supplementary Table 1). In an

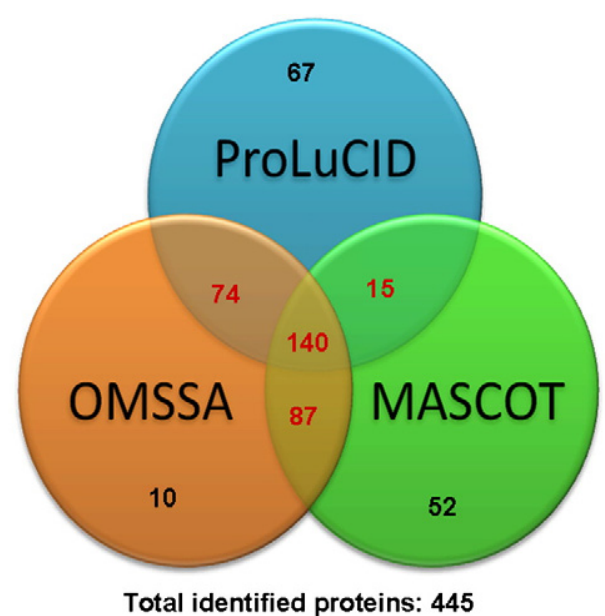

Proteins commonly identified by at least two search engines: 316

Fig. 3 - Venn diagram showing the proteins commonly identified against the Insecta (Uniref100) database using the three search engines: Mascot, OMSSA and ProLuCID. A total of 445 unique proteins were identified, 316 of which were commonly identified by at least two search engines. effort to obtain more information about these uncharacterized proteins we performed a search using the InterProScan tool to scan the PFAM Protein families database and the SMART domain database. Our results show that it was possible to assign PFAM signatures and functional domains to $94 \%$ (205/218) of the uncharacterized proteins (Supplementary Table 9). Enrichment of GO terms for the predicted functional domains of such uncharacterized proteins revealed that $43 \%$ are involved in binding, primarily in the binding of proteins and heterocyclic compounds (Supplementary Fig. 2). In addition, 13\% of predicted domains are involved in oxidoreductase activity, $12 \%$ in catalytic activity, $10 \%$ in hydrolase activity, and $6 \%$ in transferase activity, among the more represented categories.

3.3. Pheromone gland protein identification is increased by the use of a customized transcript translated database

In order to enrich our identifications, we additionally used a ProLuCID search engine to analyze the MS/MS data against our own pheromone gland transcript translated database (1387 translated sequences [35]) (Fig. 2). This search yielded 97 protein identifications (Supplementary Table 10) among which $~ 12 \%$ (12/97) were common to proteins identified by ProLuCID via the Insecta protein database. We observed that the two searching approaches obtained different portions of the proteome with little overlap between them. Searching against the Insecta Protein database gives a larger number of identifications than the transcript translated database. As transcriptome data may 


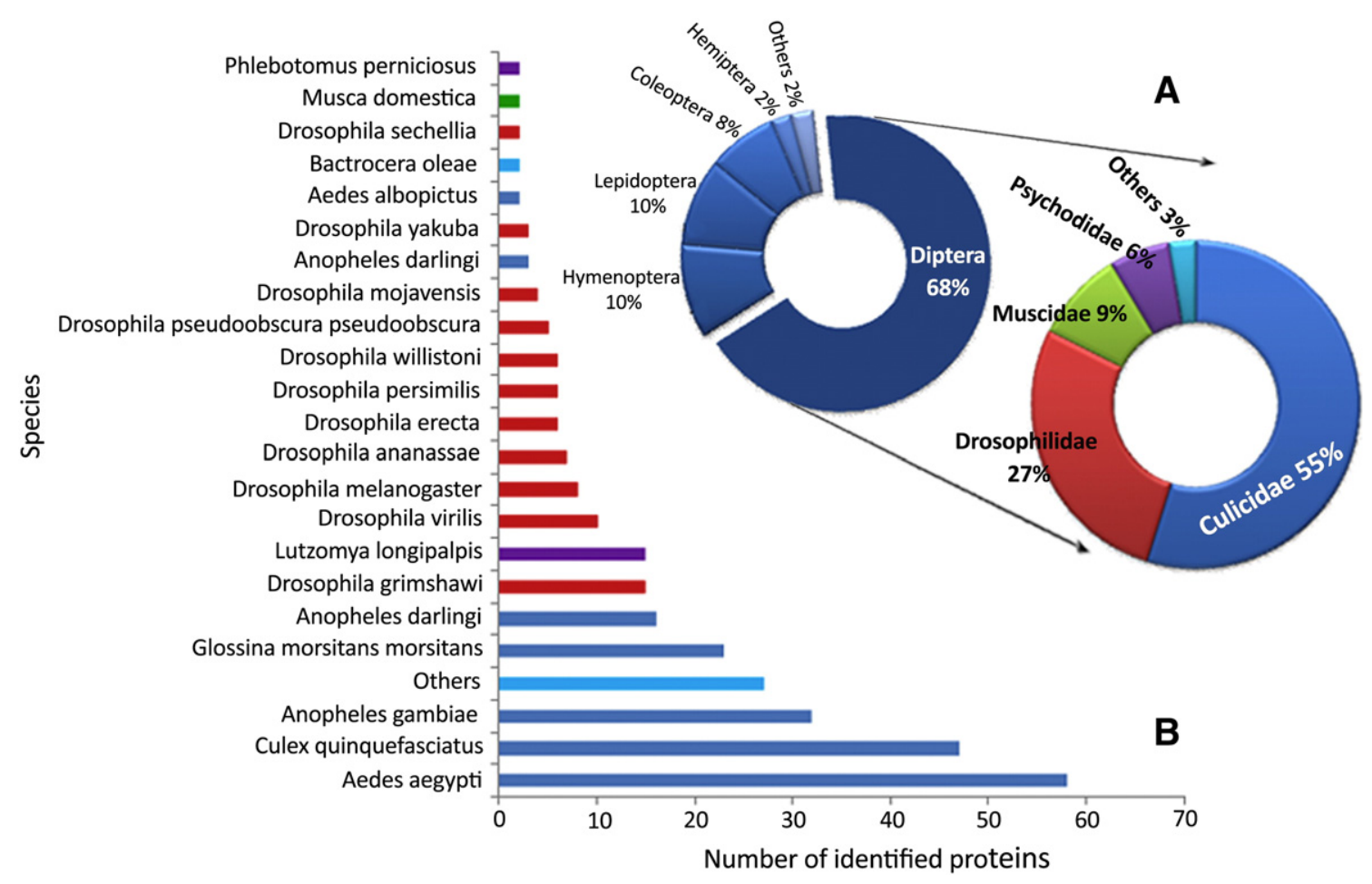

Fig. 4 - Insecta orders, families and species that contributed to the identification, by similarity, of the L. longipalpis pheromone gland proteins. (A) The Diptera order contributed 68\% identification; among Diptera, the Culicidae family contributes most of the identifications (55\%) of the L longipalpis pheromone gland proteins. (B) Species of the Culicidae (blue), Drosophilidae (red), Muscidae (green), Psychodidae (violet) and others (light blue) families that contributed for the identification of proteins from the L. longipalpis pheromone gland.

contain numerous short sequences and we set our identification to a minimum of two peptides, many protein identifications were discarded, explaining the smaller number found from the second database. However, examination using the transcript translated database allowed the identification of L. longipalpis proteins that could not be present in the Insecta protein database (Supplementary Table 10). Together, our proteomic analysis of the L. longipalpis pheromone gland generated 530 new non-redundant proteins. All data were deposited in the ProteomeXchange database.

The knowledge about L. longipalpis protein expression is very limited. Only 665 un-reviewed protein entries for Lutzomyia spp. were available at the UniProt database when we conducted the present study. The workflow used here for proteomic characterization of pheromone gland tissue in L. longipapis allowed us to report 515 new proteins for this species after discounting the 15 proteins identified as being of this species when the Insecta protein database was used. In addition, our analysis contributed to the annotation of a large portion of uncharacterized proteins. Searching against the two databases (Insecta protein database and transcript translated database) made possible the identification of proteins by increasing the chances of matches between the experimental and theoretical peptide data. Searching against the protein database derived from translation of transcript sequences of the L. longipalpis pheromone gland previously generated by our group [35] allowed a 16\% (85/530) increase in protein identification using the mass spectra of this sand fly. In addition, the use of three search engines resulted in a 2-fold increase in the number of proteins identified with a 2 peptide minimum relative to a single search engine.

3.4. The pheromone gland proteome includes enzymes of the mevalonate pathway, enzymes involved in sesquiterpenoid biosynthesis, and proteins associated to the pheromone production

The proteins identified in the pheromone gland of L. longipalpis provide interesting molecule candidates for pheromone production in this insect (Table 1). We identified six of the seven enzymes of the mevalonate pathway as well as two enzymes involved in the sesquiterpenoid backbone biosynthesis (Fig. 5) [51,52]. In addition, we identified twelve proteins that are functionally related to the mevalonate pathway or have been reported as involved in pheromone or odor metabolism such as glutaminyl-tRNA synthetase, phosphoglycerate kinase, succinyl Co-A synthetase alpha subunit, transketolase, glutathione S transferases and cytochrome family proteins [53-56] (Table 1). Functional associations among proteins potentially involved in pheromone production could be confirmed by in silico analysis using the STRING database $9.0[57,58]$. Using this tool, it was possible to obtain protein association networks for 3-hydroxy3-methylglutaryl-CoA reductase (HMGR) of A. aegypti and C. quinquefasciatus, which is the rate controlling enzyme of the mevalonate pathway [59] (Supplementary Fig. 3). All these 


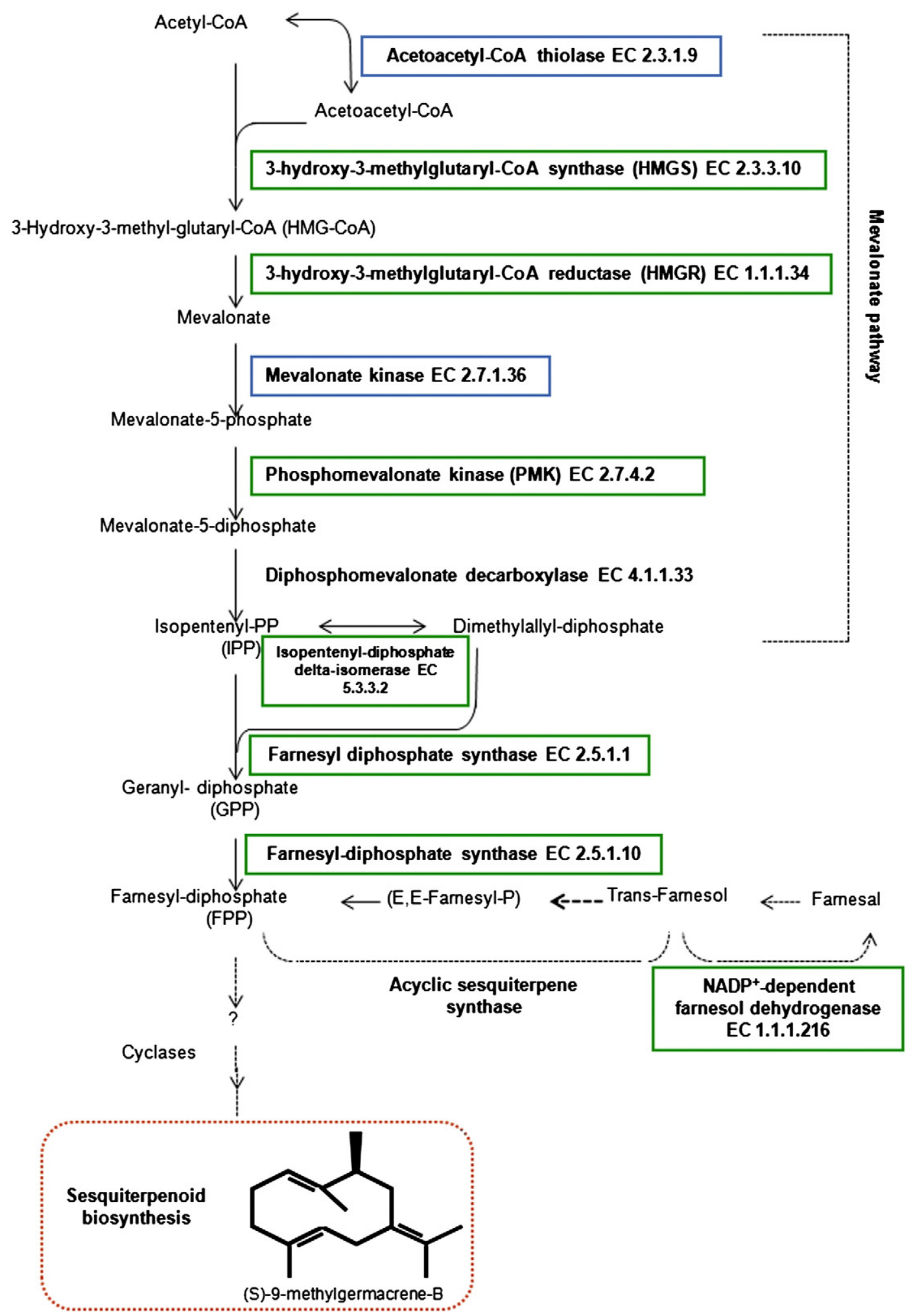

Fig. 5 - Diagram showing the mevalonate pathway and prenyltransfereases enzymes possibly related to the L. longipalpis pheromone biosynthesis. The names enclosed in boxes indicate the proteins identified in this study. Green boxes: enzymes confidently identified by at least two peptides. Blue boxes: Protein with putative thiolase-2/SCP2 sterol-binding domains identified by similarity with 4 peptides in the ant Solenopsis invicta and the bee Apis mellifera (acetoacetyl-CoA thiolase) or identified by one peptide with confident score (mevalonate kinase). For homoterpene biosynthesis, the propionyl-CoA can substitute acetyl-CoA leading to the formation of homomevalonate and consequently homofarnesyl [79]. 
potentially isoprenoid-pathway related sequences found on the pheromone gland tissue of L. longipalpis have previously been observed in other insects in the site where terpenoid production actively occurs $[55,60,61]$. Proteins with putative thiolase-2/SCP2 sterol-binding domains were identified by similarity with 4 peptides in the ant Solenopsis invicta and the bee Apis mellifera. This enzyme has been characterized in the pheromone gland of Ostrinia scapulalis [62]. The 3-hydroxy-3-methylglutaryl-CoA synthase (HMGS) was identified with 3 peptides by similarity to the enzyme of Blatella germanica in the Insecta protein database. For this insect, it has been observed that the HMGS expression is developmentally regulated and the mevalonate synthesis parallels vitellogenin production $[63,64]$. The HMGR, identified with 17 and 2 distinct peptides in C. quinquefasciatus and Drosophila persimilis, respectively, using the transcript translated database, has been reported in various Coleoptera to be involved in terpenoid pheromone production [65-69]. It has been shown that expression of HMGR in an established Drosophila cell line is regulated by mevalonate [70]. Despite having identified mevalonate kinase by similarity to Bombix mori with only 1 peptide in the Insecta protein database, we believe that this enzyme is present in the pheromone gland of L. longipalpis based on the reports of the presence of this enzyme in several sex pheromone-producing tissues in other insects [71]. The phosphomevalonate kinase (PMK) and the isopentenyldiphosphate delta-isomerase (IDI) identified by similarity to A. aegypti proteins with 3 and 11 peptides, respectively, using the transcript database, have been described in the isoprenoid synthesis pathway of B. mori [72] and in the juvenile hormone pathway in A. aegypti [73]. Furthermore we also identified an additional type of isopentenyl-diphosphate delta-isomerase having 8 peptides (Table 1, Supplementary Table 10). These results reinforce our presumption of two IDI isoforms occurring in the pheromone gland of L. longipalpis [35]. In general, the enzymes of the mevalonate pathway have also been proposed to be involved in monoterpenoid pheromone production in the beetle Ips pini and other bark beetle species [61,71]. In these insects, mevalonate pathway enzymes are regulated by feeding and by the levels of the juvenile hormone JH III [74].

The L. longipalpis pheromones (S)-9-methylgermacrene-B as well as 3-methylhimachalene are homosesquiterpenes (C16) that have a branching pattern reminiscent to those observed in the faranal, the trail pheromone of Monomorium pharaoni [75], and the lepidopteran juvenile hormones JH I and JH II [76,77]. Based on the knowledge about the biosynthesis route of these natural homoterpenoid compounds, the construction of L. longipalpis homosesquiterpenes backbone possibly requires molecules derived from homomevalonate, resulting in sesquiterpene backbone molecules with an extra methylene group $\left(\mathrm{CH}_{3}\right)$, such as the 2E,6E,8S-8-methylfarnesol proposed by Tashiro et al. in 2000 [78]. As demonstrated by Schooley et al. [79], the homomevalonate can be obtained by the condensation of propionic acids instead of acetic acid. Then, as in the classic mevalonate pathway, the homomevalonate derivatives advance through this pathway producing homofarnesyl pyrophosphate to finally generate homoterpene compounds [80]. Therefore, the occurrence of substrate specificity in L. longipalpis prenyltransferase and the cyclization of the products in the final reactions for pheromone biosynthesis represent interesting subjects for future studies.
In a previous study of the pheromone gland isolated of L. longipalpis and Lutzomyia cruzi, which is a putative L. longipalpis sibling species [81], numerous lipid droplets were described through transmission electron microscopy. Such findings were suggestive of a potential role for lipids in the pheromone synthesis, as precursors of acetyl-CoA [34,82-84]. Accordingly, our proteomic data revealed enrichment in several enzymes and proteins involved in lipid metabolism such, 3-ketoacylcoenzyme A thiolase, acyl-coenzyme A oxidase (peroxisome), acyl-coenzyme A dehydrogenase (mitochondria), hydroxyacylcoenzyme A dehydrogenase, 2-hydroxyacyl-CoA lyase 1, acetylcoenzyme A carboxylase, fatty acid synthase, fatty acid synthase S-acetyltransferase, short-chain dehydrogenase among others. We also identified acetyl-coenzyme A synthetase, which synthesizes acetyl CoA from acetate, adenosine triphosphate, and coenzyme A through an acetyl-adenosine monophosphate (AMP) intermediate $[85,86]$. Given the proximity of the fat body to the glandular cells [34], it is plausible suggest that this tissue may supply potential precursors, in the form of triacylglycerols stored in lipid droplets, for pheromone biosynthesis, as observed in moths $[87,88]$. Further studies may help to explore other functions of those lipid droplets in the $L$ longipalpis pheromone-producing cells, such as transient storage depots for proteins as observed in Drosophila [89].

\section{Conclusion}

The combination of SDS-PAGE, LC-MS/MS and a confident workflow for data mining, enabled us to perform a proteomic characterization of the 4th abdominal segment, containing the pheromone (9-methy-germacrene B)-producing cells of L. longipalpis. Considering that the annotated genome sequences of this sand fly are not yet available, we designed an alternative workflow searching MS/MS data against proteomic and transcript translated customized databases, using three search engines: Mascot, OMSSA, and ProLuCID, and further verification by PEAKS. This approach made it possible to obtain expression evidence, at the protein level, of several molecules potentially involved in the pheromone production of L. longipalpis. Having identified six of the seven enzymes of the classical mevalonate pathway and associated enzymes involved in the sesquiterpene biosynthetic pathway, we can now use a variety of tools to dissect their molecular correlation with pheromonogenesis by means of biochemical, genetic, and behavioral measurements. Additionally, our analysis also revealed a list of interesting candidate proteins that could be related to lipid metabolism, whose activity may result in providing precursors for the pheromone biosynthetic process. Most importantly, our results unraveled a range of molecules that might be directly associated with the pheromone production in L longipalpis; such molecules can now be explored as potential targets for vector control.

Supplementary data to this article can be found online at http://dx.doi.org/10.1016/j.jprot.2013.10.028.

\section{Competing interests}

The authors declare that they have no competing interests. 
Table 1 - Proteins potentially related to the Lutzomyia longipalpis pheromone biosynthesis or metabolism.

Proteins potentially related to the $\mathrm{Lu}$. longipalpis pheromone biosynthesis or metabolism

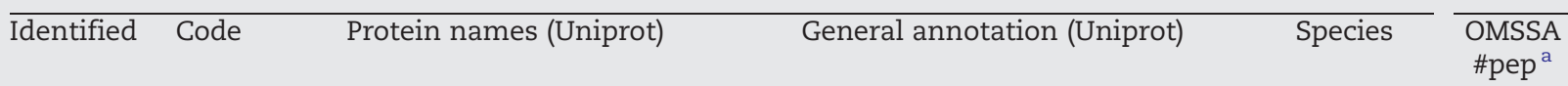

Enzymes from the mevalonate pathway

Acetoacetyl-CoA thiolase (EC 2.3.1.9)

Protein with putative Thiolase domain

Protein with putative Thiolase domain Sterol carrier protein

3-hydroxy-3-methylglutaryl-CoA synthase (EC 2.3.3.10)

3-hydroxy-3-methylglutaryl-CoA reductase (EC 1.1.1.34)

Hydroxymethylglutaryl-CoA reductase

Mevalonate kinase ${ }^{\mathrm{f}}$ (EC 2.7.1.36)

Phosphomevalonate kinase (EC 2.7.4.2)

Isopentenyl-diphosphate delta-isomerase

(EC 5.3.3.2)

Isopentenyl-diphosphate delta-isomerase

E9J2D9 Putative uncharacterized protein

H9K0HO Uncharacterized protein

Q17HG1 AAEL002687-PA

P54961 Hydroxymethylglutaryl-CoA

synthase 1

B4G517 GL23258

BOWAH3 3-hydroxy-3-methylglutaryl-coenzyme HMG-CoA reductase family. A reductase

A5A7A0 Mevalonate kinase

Q16128 AAEL013814-PA

Q1HQH4 Isopentenyl pyrophosphate:

dimethylallyl pyrophosphate isomerase

Q1HQH4 Isopentenyl pyrophosphate: dimethylallyl pyrophosphate isomerase

Enzymes involved in the sesquiterpenoid biosynthesis

Farnesyl diphosphate synthase (2.5.1.10)

Farnesyl diphosphate synthase

Farnesyl diphosphate synthase

Mitochondrial isoprenyl diphosphate synthase

NADP+-dependent farnesol dehydrogenase (1.1.1.216)

Protein with putative dehydrogenase domain
Q58GE9 Farnesyl diphosphate synthase

B3NSI9 GG22667

B3MF90 GF12409

GOYZR4 Mitochondrial isoprenyl diphosphate synthase

D2WKEO NADP+-dependent farnesol dehydrogenase 1

Q7Q6V7 AGAP005645-PA

\section{Solenopsis}

invicta

Apis mellifera

Aedes aegypti

Belongs to the HMG-CoA synthase

Blattella

family.

germanica

Belongs to the HMG-CoA reductase

family.

Belongs to the GHMP kinase family

Bombyx mori

Belongs to the FPP/GGPP synthase family. Ips pini Belongs to the FPP/GGPP synthase family Belongs to the FPP/GGPP synthase family.

Belongs to the FPP/GGPP synthase family Rhopalosiphum padi

Belongs to the short-chain dehydrogenases/reductases (SDR) family. Belongs to the short-chain Anopheles dehydrogenases/reductases (SDR) family. gambiae 
Table 1 - Proteins potentially related to the Lutzomyia longipalpis pheromone biosynthesis or metabolism.
Search engines Search on protein domain families (Pfam, SUPERFAMILY, PROSITE) databases

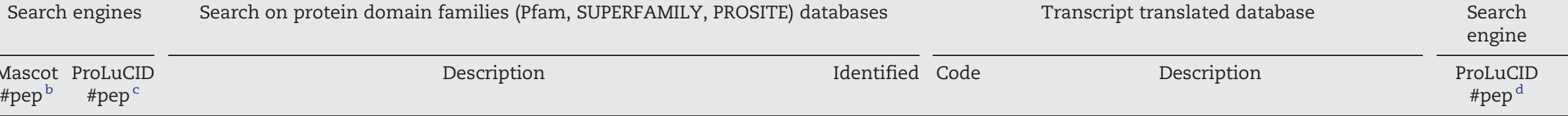

Enzymes from the mevalonate pathway

Acetoacetyl-CoA thiolase (EC 2.3.1.9) ${ }^{\mathrm{e}}$

43 Thiolase-2 (PROSITE)-SCP2 sterol-binding domain/Thiolase, N-terminal (Pfam) Thiolase-like

(SUPERFAMILY)

- 4 SCP2 sterol-binding domain/Thiolase, N-terminal (Pfam) - Thiolase-like (SUPERFAMILY)

- $\quad$ SCP2 sterol-binding domain/Thiolase-like (SUPERFAMILY) - Thiolase-2 (PROSITE) - Thiolase,

N-terminal/Thiolase, C-terminal (Pfam)

3 Hydroxymethylglutaryl-coenzyme A synthase, N-terminal/

Hydroxymethylglutaryl-coenzyme A

synthase C-terminal (Pfam) - Thiolase-like (SUPERFAMILY)

$-$

- 1 SCP2 sterol-binding domain/GHMP kinase N-terminal domain/GHMP kinase C-terminal domain

(Pfam)-Ribosomal protein S5 domain 2-like/GHMP Kinase, C-terminal domain (SUPERFAMILY)

LL-400 3-Hydroxy-3-methylglutaryl-CoA (HMG-CoA) reductase/Kog database

$+\quad$ LL-215 3-Hydroxy-3-methylglutaryl-coenzyme A reductase/NR-LIGHT database

LL-437 Phosphomevalonate kinase/NR-LIGHT database

$-$

$+\quad$ LL-53 Isopentenyl pyrophosphate:dimethylallyl pyrophosphate isomerase/Kog database

$+\quad$ LL-118 Isopentenyl pyrophosphate:dimethylallyl

pyrophosphate isomerase/Kog database

Enzymes involved in the sesquiterpenoid biosynthesis

$2 \quad-\quad$ Polyprenyl synthetase (Pfam) - Terpenoid synthases (SUPERFAMILY) 
Proteins potentially related to the $\mathrm{Lu}$. longipalpis pheromone biosynthesis or metabolism

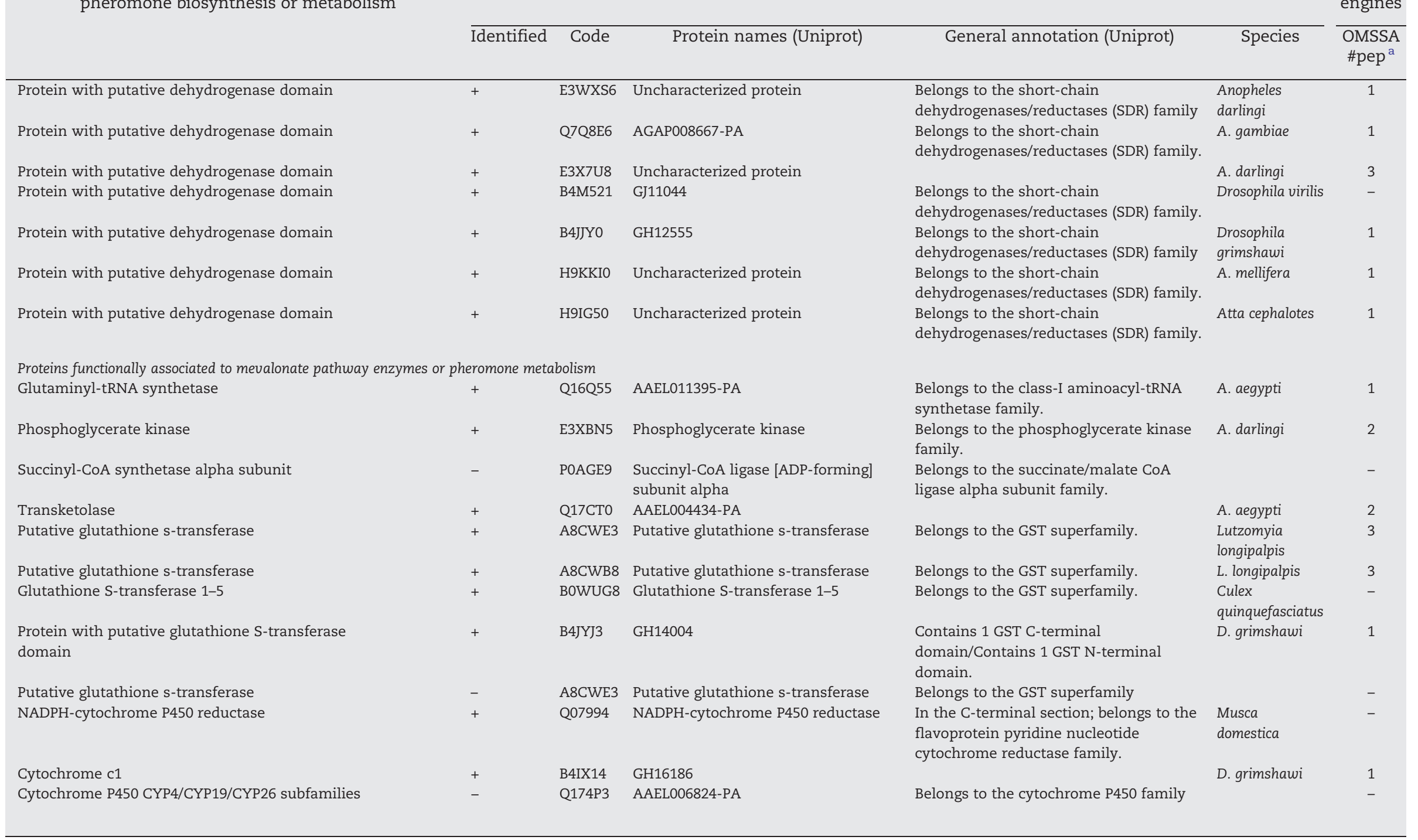




\begin{tabular}{|c|c|c|c|c|c|c|}
\hline 2 & - & Polyprenyl synthetase (Pfam) - Terpenoid synthases (SUPERFAMILY) & & & & \\
\hline - & - & & + & LL-314 & Predicted dehydrogenase/Kog database & 8 \\
\hline 2 & 2 & $\begin{array}{l}\text { Short-chain dehydrogenase/reductase SDR (Pfam) - SCP2 sterol-binding domain } \\
\text { (SUPERFAMILY) }\end{array}$ & - & - & & - \\
\hline 4 & 2 & Short-chain dehydrogenase/reductase SDR (Pfam) & - & - & & - \\
\hline- & 3 & $\begin{array}{l}\text { Short-chain dehydrogenase/reductase SDR (Pfam) - SCP2 sterol-binding domain } \\
\text { (SUPERFAMILY) }\end{array}$ & - & - & & - \\
\hline 7 & 3 & $\begin{array}{l}\text { Short-chain dehydrogenase/reductase SDR (Pfam) - SCP2 sterol-binding domain } \\
\text { (SUPERFAMILY) }\end{array}$ & - & - & & - \\
\hline 3 & 2 & $\begin{array}{l}\text { Short-chain dehydrogenase/reductase SDR (Pfam) - SCP2 sterol-binding domain } \\
\text { (SUPERFAMILY) }\end{array}$ & - & - & & - \\
\hline 3 & - & Short-chain dehydrogenase/reductase SDR (Pfam) & - & - & & - \\
\hline 2 & - & Short-chain dehydrogenase/reductase SDR (Pfam) & - & - & & - \\
\hline 3 & - & Short-chain dehydrogenase/reductase SDR (Pfam) & - & - & & - \\
\hline \multicolumn{7}{|c|}{ Proteins functionally associated to mevalonate pathway enzymes or pheromone metabolism } \\
\hline 5 & - & $\begin{array}{l}\text { Glutaminyl-tRNA synthetase, class Ib, non-specific RNA-binding domain 2/ } \\
\text { N-terminal/catalytic } \\
\text { domain (Pfam) - Ribosomal protein L25-like (SUPERFAMILY) }\end{array}$ & - & - & & - \\
\hline - & - & Phosphoglycerate kinase (Pfam) — Phosphoglycerate kinase (SUPERFAMILY) & - & - & & - \\
\hline - & - & & + & LL-149 & Succinyl-CoA synthetase, alpha subunit/Kog database & 17 \\
\hline- & 4 & $\begin{array}{l}\text { Transketolase, N-terminal/Transketolase-like, pyrimidine-binding domain } \\
\text { (Pfam) - Transketolase, C-terminal/Pyruvate-ferredoxin oxidoreductase, domain II }\end{array}$ & + & LL-363 & Transketolase/Kog database & 7 \\
\hline 7 & 4 & $\begin{array}{l}\text { Glutathione S-transferase, N and C terminal (Pfam) - Glutathione S-transferase, } \\
\text { C-terminal-like (SUPERFAMILY) }\end{array}$ & - & - & & - \\
\hline- & 3 & $\begin{array}{l}\text { Glutathione S-transferase, N and C terminal (Pfam) - Glutathione S-transferase, } \\
\text { C-terminal-like (SUPERFAMILY) }\end{array}$ & - & - & & - \\
\hline 2 & - & $\begin{array}{l}\text { Glutathione S-transferase, N and C terminal (Pfam) - Glutathione S-transferase, } \\
\text { C-terminal-like (SUPERFAMILY) }\end{array}$ & - & - & & - \\
\hline 3 & - & $\begin{array}{l}\text { EF1G/glutathione s-transferaseN and C terminal (Pfam) - Glutathione } \\
\text { S-transferase, } \\
\text { C-terminal-like (SUPERFAMILY) }\end{array}$ & - & - & & - \\
\hline - & - & & + & LL-158 & Glutathione s-transferase/Diptera database & 7 \\
\hline- & 2 & $\begin{array}{l}\text { Oxidoreductase FAD/NAD(P)-binding (Pfam) - Riboflavin synthase-like beta-barrel } \\
\text { (SUPERFAMILY) }\end{array}$ & - & - & & - \\
\hline 2 & 1 & Cytochrome c1 (Pfam) - Cytochrome c domain (SUPERFAMILY) & - & - & & - \\
\hline- & - & & + & LL-42 & $\begin{array}{l}\text { Cytochrome P450 CYP4/CYP19/CYP26 subfamilies/Kog } \\
\text { database }\end{array}$ & 5 \\
\hline
\end{tabular}




\section{Acknowledgments}

This work was funded by the Coordenação de Aperfeiçoamento de Pessoal de Nivel Superior (CAPES), Fundação de Amparo à Pesquisa do Estado do Rio de Janeiro (FAPERJ) and Programa de Desenvolvimento Tecnológico em Insumos para Saúde (PDTIS-Fiocruz). J.M.C.R. and J.G.V. were supported by the Intramural Research Program of the Division of Intramural Research, NIAID, National Institutes of Health. Because J.M.C.R. and J.G.V. are government employees and this is a government work, the work is in the public domain in the United States. Notwithstanding any other agreements, the $\mathrm{NIH}$ reserves the right to provide the work to PubMedCentral for display and use by the public, and PubMedCentral may tag or modify the work consistent with its customary practices. You can establish rights outside of the U.S. subject to a government use license. The funders had no role in the study design, data collection and analysis, decision to publish or preparation of the manuscript. We thank Francisco de Assis Marra and Andressa Fuzari Rodrigues for their assistance with the insect maintenance and dissection, respectively. We are grateful also to Dr. Aniel Sanchez (CIGB, Cuba) for the help with the Mascot searches, and to the colleagues of the Laboratorio de Pesquisa em Leishmaniose for their help with the protein purification and discussions.

\section{R E F E R E N C E S}

[1] Alvar J, Vélez ID, Bern C, Herrero M, Desjeux P, Cano J, et al. Leishmaniasis worldwide and global estimates of its incidence. PLoS One 2012;7:e35671.

[2] Kuhls K, Alam MZ, Cupolillo E, Ferreira GEM, Mauricio IL, Oddone R, et al. Comparative microsatellite typing of new world Leishmania infantum reveals low heterogeneity among populations and its recent old world origin. PLoS Negl Trop Dis 2011;5:e1155.

[3] Lainson R, Rangel EF. Lutzomyia longipalpis and the eco-epidemiology of American visceral leishmaniasis, with particular reference to Brazil: a review. Mem Inst Oswaldo Cruz 2005;100:811-27.

[4] Galati E. Morfologia e taxonomia: Classificação de flebotominae. In: Rangel E, Lainson R, editors. Flebotomineos do Brasil. Rio de Janeiro: Editora Fiocruz; 2003. p. 23-52.

[5] Young DG, Duncan MA. Guide to the identification and geographic distribution of Lutzomyia sand flies in Mexico, the West Indies, Central and South America (Diptera: Psychodidae). Memoirs of the American Entomological Institute. Gainesville: Associated Publishers; 1994.

[6] Grimaldi G, Tesh RB, McMahon-Pratt D. A review of the geographic distribution and epidemiology of leishmaniasis in the New World. Am J Trop Med Hyg 1989;41:687-725.

[7] Killick-Kendrick R. The biology and control of phlebotomine sand flies. Clin Dermatol 1999;17:279-89.

[8] Brazil RP, Brazil BG. Biologia de Flebotomíneos Tropicais. In: Rangel E, Lainson R, editors. Flebotomíneos do Brasil. Rio de Janeiro: Editora Fiocruz; 2003. p. 257-74.

[9] Oliveira EF, Silva EA, Casaril AE, Fernandes CES, Paranhos Filho AC, Gamarra RM, et al. Behavioral aspects of Lutzomyia longipalpis (Diptera: Psychodidae) in urban area endemic for visceral leishmaniasis. J Med Entomol 2013;50:277-84.

[10] Jeronimo SMB, Duggal P, Braz RFS, Cheng C, Monteiro GRG, Nascimento ET, et al. An emerging peri-urban pattern of infection with Leishmania chagasi, the protozoan causing visceral leishmaniasis in Northeast Brazil. Scand J Infect Dis 2004;36:443-9.

[11] Werneck GL. Expansão geográfica da leishmaniose visceral no Brasil. Cad Saude Publica 2010;26:644-5.

[12] Humberg RM, Oshiro ET, Cruz Mdo S, Ribolla PE, Alonso DP, Ferreira AM, et al. Leishmania chagasi in opossums (Didelphis albiventris) in an urban area endemic for visceral leishmaniasis, Campo Grande, Mato Grosso do Sul, Brazil. Am J Trop Med Hyg 2012;87:470-2.

[13] Kelly DW, Dye C. Pheromones, kairomones and the aggregation dynamics of the sandfly Lutzomyia longipalpis. Anim Behav 1997;53:721-31.

[14] Bray DP, Hamilton JGC. Host odor synergizes attraction of virgin female Lutzomyia longipalpis (Diptera: Psychodidae). J Med Entomol 2007;44:779-87.

[15] Hamilton JGC, Dawson GW, Pickett JA. 3-Methyl- $\alpha$-himachalene: proposed structure for novel homosesquiterpene sex pheromone of Lutzomyia longipalpis (diptera: Psychodidae) from Jacobina, Brazil. J Chem Ecol 1996;22:2331-40.

[16] Hamilton JGC, Dawson GW, Pickett JA. 9-Methylgermacrene-B; proposed structure for novel homosesquiterpene from the sex pheromone glands of Lutzomyia longipalpis (Diptera: Psychodidae) from Lapinha, Brazil. J Chem Ecol 1996;22:1477-91.

[17] Hamilton JGC, Ibbotson HC, Hooper AM, Pickett JA. 9-Methylgermacrene-B is confirmed as the sex pheromone of the sandfly Lutzomyia longipalpis from Lapinha, Brazil, and the absolute stereochemistry defined as S. Chem Commun 1999:2335-6.

[18] Hamilton JGC, Hooper AM, Pickett JA, Mori K, Sano S. 3-Methyl- $\alpha$-himachalene is confirmed, and the relative stereochemistry defined, by synthesis as the sex pheromone of the sandfly Lutzomyia longipalpis from Jacobina, Brazil. Chem Commun 1999:355-6.

[19] Hamilton JG, Brazil RP, Maingon R. A fourth chemotype of Lutzomyia longipalpis (Diptera: Psychodidae) from Jaibas, Minas Gerais State, Brazil. J Med Entomol 2004;41:1021-6.

[20] Hamilton JG, Maingon RD, Alexander B, Ward RD, Brazil RP. Analysis of the sex pheromone extract of individual male Lutzomyia longipalpis sandflies from six regions in Brazil. Med Vet Entomol 2005;19:480-8.

[21] Cane DE. Isoprenoid biosynthesis: overview. In: Otto Meth-Cohn SDB, Koji N, editors. Comprehensive natural products chemistry. Oxford: Pergamon; 1999. p. 1-13.

[22] Goldstein JL, Brown MS. Regulation of the mevalonate pathway. Nature 1990;343:425-30.

[23] Bochar DA, Freisen J, Stauffacher CV, Rodwell VW. Biosynthesis of mevalonic acid from acetyl-CoA. In: Otto Meth-Cohn SDB, Koji N, editors. Comprehensive natural products chemistry. Oxford: Pergamon; 1999. p. 15-44.

[24] Kircher H. In: Dupont J, editor. Cholesterol systems in insects and animals. Boca Raton: CRC Press, Inc.; 1982. p. 1-50.

[25] Beenakkers AM, Van der Horst DJ, Van Marrewijk WJ. Insect lipids and lipoproteins, and their role in physiological processes. Prog Lipid Res 1985;24:19-67.

[26] Clark AJ, Bloch $\mathrm{K}$. The absence of sterol synthesis in insects. J Biol Chem 1959;234:2578-82.

[27] Santos AC, Lehmann R. Isoprenoids control germ cell migration downstream of HMGCoA reductase. Dev Cell 2004;6:283-93.

[28] Bellés X, Martin D, Piulachs MD. The mevalonate pathway and the synthesis of juvenile hormone in insects. Annu Rev Entomol 2005;50:181-99.

[29] Feyereisen R. Regulation of juvenile hormone titer: synthesis. In: Kerkut G, Gilbert L, editors. Comprehensive insect physiology, biochemistry and pharmacology. Oxford: Pergamon Press; 1985. p. 391-429. 
[30] Schooley D, Baker F. Juvenile hormone biosynthesis. In: Kerkut G, Gilbert L, editors. Comprehensive insect physiology, biochemistry and pharmacology. Oxford: Pergamon Press; 1985. p. 363-89.

[31] Ueda H, Shinoda T, Hiruma K. Spatial expression of the mevalonate enzymes involved in juvenile hormone biosynthesis in the corpora allata in Bombyx mori. J Insect Physiol 2009;55:798-804.

[32] Nouzova M, Edwards MJ, Mayoral JG, Noriega FG. A coordinated expression of biosynthetic enzymes controls the flux of juvenile hormone precursors in the corpora allata of mosquitoes. Insect Biochem Mol Biol 2011;41:660-9.

[33] Lane RP, Bernardes DS. Histology and ultrastructure of pheromone secreting glands in males of the phlebotomine sandfly Lutzomyia longipalpis. Ann Trop Med Parasitol 1990;84:53-61.

[34] Spiegel CN, Batista-Pereira LG, Bretas JAC, Eiras ÁE, Hooper AM, Pelxoto AA, et al. Pheromone gland development and pheromone production in Lutzomyia longipalpis (Diptera: Psychodidae: Phlebotominae). J Med Entomol 2011;48:489-95.

[35] Gonzalez-Caballero N, Valenzuela JG, Ribeiro JM, Cuervo P, Brazil RP. Transcriptome exploration of the sex pheromone gland of Lutzomyia longipalpis (Diptera: Psychodidae: Phlebotominae). Parasit Vectors 2013;6:56.

[36] Cuervo P, De Jesus JB, Saboia-Vahia L, Mendonça-Lima L, Domont GB, Cupolillo E. Proteomic characterization of the released/secreted proteins of Leishmania (Viannia) braziliensis promastigotes. J Proteomics 2009;73:79-92.

[37] Carvalho PC, Fischer JSG, Xu T, Cociorva D, Balbuena TS, Valente RH, et al. Search engine processor: filtering and organizing peptide spectrum matches. Proteomics 2012;12:944-9.

[38] Carvalho PC, Yates III JR, Barbosa VC. Analyzing shotgun proteomic data with PatternLab for proteomics. Current protocols in bioinformatics. John Wiley \& Sons, Inc.; 2010

[39] Geer LY, Markey SP, Kowalak JA, Wagner L, Xu M, Maynard $\mathrm{DM}$, et al. Open mass spectrometry search algorithm. J Proteome Res 2004;3:958-64.

[40] Specht M, Kuhlgert S, Fufezan C, Hippler M. Proteomics to go: proteomatic enables the user-friendly creation of versatile MS/MS data evaluation workflows. Bioinformatics 2011;27:1183-4.

[41] Suzek BE, Huang H, McGarvey P, Mazumder R, Wu CH. UniRef: comprehensive and non-redundant UniProt reference clusters. Bioinformatics 2007;23:1282-8.

[42] Carvalho PC, Fischer JS, Chen EI, Domont GB, Carvalho MG, Degrave WM, et al. GO Explorer: a gene-ontology tool to aid in the interpretation of shotgun proteomics data. Proteome Sci 2009;7:6.

[43] Zdobnov EM, Apweiler R. InterProScan - an integration platform for the signature-recognition methods in InterPro. Bioinformatics 2001;17:847-8.

[44] Goujon M, McWilliam H, Li W, Valentin F, Squizzato S, Paern J, et al. A new bioinformatics analysis tools framework at EMBL-EBI. Nucleic Acids Res 2010;38:W695-9.

[45] Taylor CF, Paton NW, Lilley KS, Binz P-A, Julian RK, Jones AR, et al. The minimum information about a proteomics experiment (MIAPE). Nat Biotech 2007;25:887-93.

[46] Jones P, Côté RG, Cho SY, Klie S, Martens L, Quinn AF, et al. PRIDE: new developments and new datasets. Nucleic Acids Res 2008;36:D878-83.

[47] Huizinga DH, Omosegbon O, Omery B, Crowell DN. Isoprenylcysteine methylation and demethylation regulate abscisic acid signaling in Arabidopsis. Plant Cell 2008;20:2714-28.

[48] Freije JM, Blay P, Pendas AM, Cadinanos J, Crespo P, Lopez-Otin C. Identification and chromosomal location of two human genes encoding enzymes potentially involved in proteolytic maturation of farnesylated proteins. Genomics 1999;58:270-80.
[49] Fraga BM. Natural sesquiterpenoids. Nat Prod Rep 2008;25:1180-209.

[50] Mayoral JG, Nouzova M, Navare A, Noriega FG. NADP +-dependent farnesol dehydrogenase, a corpora allata enzyme involved in juvenile hormone synthesis. Proc Natl Acad Sci U S A 2009;106:21091-6.

[51] Vandermoten S, Haubruge E, Cusson M. New insights into short-chain prenyltransferases: structural features, evolutionary history and potential for selective inhibition. Cell Mol Life Sci 2009;66:3685-95.

[52] Bhandari J, Fitzpatrick AH, Crowell DN. Identification of a novel abscisic acid-regulated farnesol dehydrogenase from Arabidopsis. Plant Physiol 2010;154:1116-27.

[53] Sutherland TD, Unnithan GC, Andersen JF, Evans PH, Murataliev MB, Szabo LZ, et al. A cytochrome P450 terpenoid hydroxylase linked to the suppression of insect juvenile hormone synthesis. Proc Natl Acad Sci U S A 1998;95:12884-9.

[54] López MF, Cano-Ramírez C, Cesar-Ayala AK, Ruiz EA, Zúñiga G. Diversity and expression of P450 genes from Dendroctonus valens LeConte (Curculionidae: Scolytinae) in response to different kairomones. Insect Biochem Mol Biol 2013;43:417-32.

[55] Keeling CI, Henderson H, Li M, Yuen M, Clark EL, Fraser JD, et al. Transcriptome and full-length cDNA resources for the mountain pine beetle, Dendroctonus ponderosae Hopkins, a major insect pest of pine forests. Insect Biochem Mol Biol 2012;42:525-36.

[56] Robertson H, Martos R, Sears C, Todres E, Walden K, Nardi J. Diversity of odourant binding proteins revealed by an expressed sequence tag project on male Manduca sexta moth antennae. Insect Mol Biol 1999;8:501-18.

[57] Jensen LJ, Kuhn M, Stark M, Chaffron S, Creevey C, Muller J, et al. STRING 8 - a global view on proteins and their functional interactions in 630 organisms. Nucleic Acids Res 2009;37:D412-6.

[58] Szklarczyk D, Franceschini A, Kuhn M, Simonovic M, Roth A, Minguez P, et al. The STRING database in 2011: functional interaction networks of proteins, globally integrated and scored. Nucleic Acids Res 2011;39:D561-8.

[59] Wang Z, Dong Y, Desneux N, Niu C. RNAi silencing of the HaHMG-CoA reductase gene inhibits oviposition in the Helicoverpa armigera cotton bollworm. PLoS One 2013;8:e67732.

[60] Hojo M, Maekawa K, Saitoh S, Shigenobu S, Miura T, Hayashi $Y$, et al. Exploration and characterization of genes involved in the synthesis of diterpene defence secretion in nasute termite soldiers. Insect Mol Biol 2012;21:545-57.

[61] Keeling C, Blomquist G, Tittiger C. Coordinated gene expression for pheromone biosynthesis in the pine engraver beetle, Ips pini (Coleoptera: Scolytidae). Naturwissenschaften 2004;91:324-8.

[62] Fujii T, Ito K, Katsuma S, Nakano R, Shimada T, Ishikawa Y. Molecular and functional characterization of an acetyl-CoA acetyltransferase from the adzuki bean borer moth Ostrinia scapulalis (Lepidoptera: Crambidae). Insect Biochem Mol Biol 2010;40:74-8.

[63] Buesa C, Martínez-Gonzalez J, Casals N, Haro D, Piulachs MD, Bellés X, et al. Blattella germanica has two HMG-CoA synthase genes. Both are regulated in the ovary during the gonadotrophic cycle. J Biol Chem 1994;269:11707-13.

[64] Nr Casals, Buesa C, Piulachs M-D, Cabanó J, Marrero PF, Belles X, et al. Coordinated expression and activity of 3-hydroxy-3-methylglutaryl coenzyme a synthase and reductase in the fat body of Blattella germanica (L.) during vitellogenesis. Insect Biochem Mol Biol 1996;26:837-43.

[65] Taban AH, Fu J, Blake J, Awano A, Tittiger C, Blomquist GJ. Site of pheromone biosynthesis and isolation of HMG-CoA reductase cDNA in the cotton boll weevil, Anthonomus grandis. Arch Insect Biochem Physiol 2006;62:153-63.

[66] Hall GM, Tittiger C, Andrews GL, Mastick GS, Kuenzli M, Luo $\mathrm{X}$, et al. Midgut tissue of male pine engraver, Ips pini, 
synthesizes monoterpenoid pheromone component ipsdienol de novo. Naturwissenschaften 2002;89:79-83.

[67] Hall GM, Tittiger C, Blomquist GJ, Andrews GL, Mastick GS, Barkawi LS, et al. Male Jeffrey pine beetle, Dendroctonus jeffreyi, synthesizes the pheromone component frontalin in anterior midgut tissue. Insect Biochem Mol Biol 2002;32:1525-32.

[68] Nardi J, Young AG, Ujhelyi E, Tittiger C, Lehane M, Blomquist G. Specialization of midgut cells for synthesis of male isoprenoid pheromone components in two scolytid beetles, Dendroctonus jeffreyi and Ips pini. Tissue Cell 2002;34:221-31.

[69] Ivarsson P, Tittiger C, Blomquist C, Borgeson CE, Seybold SJ, Blomquist GJ, et al. Pheromone precursor synthesis is localized in the metathorax of Ips paraconfusus Lanier (Coleoptera: Scolytidae). Naturwissenschaften 1998;85:507-11.

[70] Silberkang M, Havel CM, Friend DS, McCarthy BJ, Watson JA. Isoprene synthesis in isolated embryonic Drosophila cells. I. Sterol-deficient eukaryotic cells. J Biol Chem 1983;258:8503-11.

[71] Blomquist GJ, Figueroa-Teran R, Aw M, Song M, Gorzalski A, Abbott NL, et al. Pheromone production in bark beetles. Insect Biochem Mol Biol 2010;40:699-712.

[72] Kinjoh T, Kaneko Y, Itoyama K, Mita K, Hiruma K, Shinoda T. Control of juvenile hormone biosynthesis in Bombyx mori: cloning of the enzymes in the mevalonate pathway and assessment of their developmental expression in the corpora allata. Insect Biochem Mol Biol 2007;37:808-18.

[73] Diaz ME, Mayoral JG, Priestap H, Nouzova M, Rivera-Perez C, Noriega FG. Characterization of an isopentenyl diphosphate isomerase involved in the juvenile hormone pathway in Aedes aegypti. Insect Biochem Mol Biol 2012;42:751-7.

[74] Bearfield J, Henry A, Tittiger C, Blomquist G, Ginzel M. Two regulatory mechanisms of monoterpenoid pheromone production in Ips spp. of bark beetles. J Chem Ecol 2009;35:689-97.

[75] Ritter FJ, Brüggemann-Rotgans IEM, Verwiel PEJ, Persoons CJ, Talman E. Trail pheromone of the Pharaoh's ant, Monomorium pharaonis: isolation and identification of faranal, a terpenoid related to juvenile hormone II. Tetrahedron Lett 1977;18:2617-8.

[76] Meyer AS, Schneiderman HA, Hanzmann E, Ko JH. The two juvenile hormones from the Cecropia silk moth. Proc Natl Acad Sci U S A 1968;60:853-60.

[77] Meyer AS, Hanzmann E, Schneiderman HA, Gilbert LI, Boyette $\mathrm{M}$. The isolation and identification of the two juvenile hormones from the Cecropia silk moth. Arch Biochem Biophys 1970;137:190-213.

[78] Tashiro T, Bando M, Mori K. Pheromone synthesis, CCVIII: synthesis of (1S, 3S, 7R)-3-methyl- $\alpha$-himachalene, the sex pheromone of the sandfly Lutzomyia longipalpis from Jacobina, Brazil. Synthesis 2000;13:1852-62.

[79] Schooley DA, Judy KJ, Bergot BJ, Hall MS, Siddall JB. Biosynthesis of the juvenile hormones of Manduca sexta: labeling pattern from mevalonate, propionate, and acetate. Proc Natl Acad Sci U S A 1973;70:2921-5.

[80] Francke W, Schulz S. Pheromones. Comprehensive natural products chemistry, 8; 1999. p. 197-261.

[81] Vigoder FM, Araki AS, Bauzer LGSR, Souza NA, Brazil RP, Peixoto AA. Lovesongs and period gene polymorphisms indicate Lutzomyia cruzi (Mangabeira, 1938) as a sibling species of the Lutzomyia longipalpis (Lutz and Neiva, 1912) complex. Infect Genet Evol 2010;10:734-9.

[82] Spiegel CN, Brazil RP, Soares MJ. Ultrastructure of male sex pheromone glands in abdominal tergites of five Lutzomyia sandfly species (Diptera: Psychodidae). Arthropod Struct Dev 2002;30:219-27.

[83] Spiegel CN, Brazil RP, Soares MJ. Ultrastructural cytochemistry of the sex pheromone glands of Lutzomyia cruzi male sand flies (Diptera: Psychodidae: Phlebotominae). Arthropod Struct Dev 2004;33:399-404.

[84] Boufana B, Ward R, Phillips A. Development of the tergal pheromone gland in male Lutzomyia longipalpis (Diptera: Psychodidae). Trans R Soc Trop Med Hyg 1986;80:333-44.

[85] Millerd A, Bonner J. Acetate activation and acetoacetate formation in plant systems. Arch Biochem Biophys 1954;49:343-55.

[86] Starai VJ, Celic I, Cole RN, Boeke JD, Escalante-Semerena JC. Sir2-dependent activation of acetyl-CoA synthetase by deacetylation of active lysine. Science 2002;298:2390-2.

[87] Matsumoto S, Fónagy A, Yamamoto M, Wang F, Yokoyama N, Esumi Y, et al. Chemical characterization of cytoplasmic lipid droplets in the pheromone-producing cells of the silkmoth, Bombyx mori. Insect Biochem Mol Biol 2002;32:1447-55.

[88] Fónagy A, Yokoyama N, Matsumoto S. Physiological status and change of cytoplasmic lipid droplets in the pheromone-producing cells of the silkmoth, Bombyx mori (Lepidoptera, Bombycidae). Arthropod Struct Dev 2001;30:113-23.

[89] Cermelli S, Guo Y, Gross SP, Welte MA. The lipid-droplet proteome reveals that droplets are a protein-storage depot. Curr Biol 2006;16:1783-95.

[90] Zhang J, Xin L, Shan B, Chen W, Xie M, Yuen D, et al. PEAKS DB: de novo sequencing assisted database search for sensitive and accurate peptide identification. Mol Cell Proteomics 2012;11 [M111.010587]. 